\title{
DIAGNOSIS AND TREATMENT OF NECROTIZING ENTEROCOLITIS IN NEWBORNS LITERATURE REVIEW
}

\section{Davud Magomedmirzaev ${ }^{*}$, Alexey Zhidovinov, Pavel Permyakov, Misrikhan Misrikhanov, Natalia Petruk, Khadizhat Vakhabova, Bairta Shavarikova, Zemfira Balayeva, Elkhan Aliev}

Astrakhan State Medical University, Astrakhan, Russia

*Corresponding Author: davudmagomedmirzaev@yandex.ru

ABSTRACT - A literature review of ulcerative necrotizing enterocolitis, which is one of the most urgent problems in the structure of pathology of newborns surgical profile is presented. The relevance is due to the high prevalence of ulcerative - necrotizing enterocolitis, difficulties in its diagnosis, conservative and surgical treatment, high mortality and frequent complications by perforation to the abdominal cavity and other organs.

KEYWORDS - NEC, newborns, review, treatment, diagnosis

Determination, pathogenesis and prevalence of ulcerativenecrotizing enterocolitis in newborns

Ulcerative necrotizing enterocolitis (NEC) is an inflammatory disease of newborns which is accompanied by damage to the gastrointestinal tract (GIT) with the development of perforations and intestinal necrosis. Despite the progress made in diagnosis and treatment, the mortality of patients with NEC after surgery is high, and reaches $60 \%$ and does not tend to decrease $[8,11,14,17,18,26]$.

To date, the etiology and pathogenesis of NEC has been the subject of extensive scientific discussion. The main efforts are aimed at finding potential markers to identify NEC in the early stages, to determine the nature of the course and prognosis of the disease $[3,8]$.

Despite the progress achieved in the diagnosis, the analysis of the immediate and long - term results of treatment of NEC shows that in 16-40\% of children the course of the disease is complicated by perforations of the gastrointestinal tract, the mortality in which reaches according to different authors from $40-90 \%$ [8, 11, 14, 27, 18, 19, 23, 27]. It becomes quite obvious that the success of treatment depends not only on adequate surgical correction, timely and rational prescription of antibiotics, but also is determined by a complex of diagnostic and therapeutic measures aimed at early detection of signs of complicated course of NEC $[2,3,4,9,10,21,22,24]$.

It is known that in NEC any parts of the gastrointestinal tract (GIT) can be damaged. The prevailing pathological process in more than $90 \%$ of cases is inflammation and coagulation necrosis of the intestinal wall. The proven risk factors in the pathogenesis of NEC are prematurity, early onset of feeding, asphyxia, intestinal ischemia, immune disorders and infection, and low gestational age $[1,7,20,25,29]$.

The role of other risk factors, their interrelation and consistency, remains unclear.

In the 1960s, when describing a series of newborns and infants with gastrointestinal perforations, it was found that most patients had clinical signs of neonatal hypoxia, which was considered the main cause of NEC the development of NEC Further accumulation of data suggested that possible producing factors of NEC in premature infants are intestinal hypoperfusion caused by congenital defects of the cardiovascular system, hypoxic-ischemic lesions of the Central nervous system, polycythemia, persistent circulatory disorders in the upper mesenteric artery $[20,28]$.

Endothelial cells (EC) play a key role in the regulation of blood flow, permeability and intercellular metabolism. In experimental models of NEC, EC damage has been revealed as a result of edema, cytoskeleton disorders, depolarization and increased permeability of cytomembranes caused by active oxygen forms and proinflammatory mediators, the excess production of which is the result of stimulation of the immune system, which leads to microcirculatory dysfunction in NEC.

The mechanisms of development of ischemic intestinal damage in NEC are directly related to inflammatory changes in the intestinal wall due to the development of acute inflammation manifested by leukocyte infiltration. Interstitial neutrophils appear to be the main producers of active types of oxygen, proteases and inflammatory cytokines, which contribute to further damage to the intestine, increasing immune inflammation. Interestingly, neutrophil infiltration are largely restricted to post-capillary venules, which confirms the observation that only $0.6 \%$ of leukocytes pass through the arterioles in comparison with 39\% 
in venules. In addition, the endothelium venul is more sensitive to the effects of leukocyte producers than the endothelium of arterioles and capillaries [29, 30, 32].

Thus, ischemia is not the only initiating factor in the development of NEC in most cases, but it plays an important role at all stages of development of NEC. Sharp changes in hemodynamics after birth and immature control system of mesenteric blood circulation, especially in premature infants, makes mesenteric vessels vulnerable. Postpartum stress easily disrupts the function of the endothelium, which leads to microcirculatory dysfunction of the intestine, manifested by vasoconstriction of arterioles, violation of the endothelial barrier in the capillaries, inflammatory cell infiltration of the intestinal wall. With prolonged exposure to damaging factors, microcirculation disorders progress to coagulation necrosis, ultimately determining the direction of NEC $[6,13,29,31]$.

Experimental studies on cell cultures from resected drugs of the intestine of newborns with NEC has allowed to establish that fetuses and preterm infants excessive inflammatory response to postnatal microbial colonization, accompanied by damage of the epithelial intestinal cells $[6,13]$.

Excessive intestinal damage due to inadequate inflammatory response associated with abnormal intestinal flora is now considered to be the most likely basis for the pathogenesis of necrotizing enterocolitis $[7,10,13]$.

The main objective of the examination of children with NEC is to identify symptoms that allow to determine indications for surgery as early as possible before the development of intestinal perforations and peritonitis $[5,12,15,16,18]$.

Currently, the absolute indications for surgical treatment of newborns with NEC, taking into account all signs of the disease, can be distributed in the degree of importance and frequency of occurrence as follows:

1. Inflammatory changes in the abdominal wall, pronounced subcutaneous venous network, tension and soreness in palpation of the abdomen, which usually indicate the presence of peritonitis, gangrene of the intestine adjacent to the abdominal abscess;

2. Pneumoperitoneum - a direct sign of perforation in combination with other signs of NEC;

3. Specific $x$-ray picture, indicating the gangrene of the intestine - the presence of a static loop of the intestine, uneven inflation of the intestinal loops, common pneumatosis of the intestinal wall, gas in the portal vein, signs of suddenly arisen ascites;

4. Laparocentesis data - cloudy brown or greenish effusion with a high content of leukocytes and extracellular bacteria;
5. Inflammatory infiltrate in the abdominal cavity with signs of abscess or intestinal obstruction, indicating the presence of conglomerate soldered together necrotizing intestinal loops;

6. Laboratory data - acute thrombocytopenia, hemocoagulation disorders, severe hyponatremia and persistent metabolic acidosis.

\section{Relative indications for surgery are:}

1. Clinical deterioration of the patient;

2. Severe thrombocytopenia;

3. Profuse bleeding from the lower gastrointestinal tract;

4. Persistent tension of the anterior abdominal wall;

5. A sharp decrease in gas filling of intestinal loops in the presence of signs of ascites.

Despite the clearly defined indications for surgical treatment, the results of clinical observations indicate that the choice of terms and optimal methods of surgical treatment of NEC is the subject of discussion. One of the priority directions of research of the pathogenesis of NEC is the search for reliable molecular markers that can adequately determine the severity of the disease in order to determine the outcomes and the choice of individual treatment tactics [30].

Thus, the above shows that there is no single algorithm of medical diagnostic measures in NEC in newborns. Optimization of early diagnosis and treatment of NEC is an urgent task of neonatologists and pediatric surgeons.

\section{REFERENCES}

1. AgEeva, O. A. Necrotizing enterocolitis in extremely premature. / O. A. Adeeva / / Medical Bulletin of the North Caucasus. - 2009. - Vol. 1, № 1. - P. 147.

2. Alekhina, L. A. Necrotizing enterocolitis in extremely premature children: issues and possible solutions. / L. A. Alekhina/ / Bulletin of the Federal center for heart, blood and endocrinology them. V.A. Almazov. - 2010. - № 6. - P. 2.

3. Arapova, A. V. Olkhova, E. B., Schitinin, V. E. Ulcero- necrotizing enterocolitis in newborns. /A. V. Arapova, E. B.Olkhova, V. E. Schitinin // Pediatric surgery. - 2003. - № 1. - P. 11-15

4. Arapova, A. V., Schitinin, B. E., Tumanyan, G. T. Ultrasound diagnosis in emergency abdominal surgery in newborns./The A.V. Arapova, B. E. Schitinin, Tumanyan G. T.// Pediatric surgery. - 2003. - № 6. - P. $42-46$.

5. AKhramovich, R. V. Results of surgical treatment of ulcerative-necrotizing enterocolitis. / R. V. Akhramovich / / Medical Bulletin of the North Caucasus. 2009. - Vol. 1, № 1. - S. 147-148.

6. Bulgakova, L. G., Nemirovskaya, E. M., Agafonova, E. A. Analysis of the clinical course of ulcerative necrotizing enterocolitis complicated by peritonitis. /L. G. Bulgakova, E. M. Nemirovskaya, E. 
A. Agafonova, / / Questions of modern Pediatrics. 2006. - № 5. - P. 88.

7. Bushtyrev, V. A., Laura, N. B., Zakharova, N.I. Score the health status of preterm infants with perinatal infections. /V. A. Bushtyrev, N. B. Laura, N. I. Zakharova// Russian Bulletin of Perinatology and Pediatrics. - 2006. - №3. - P. 11-14.

8. Volodin, N. N. Actual problems of neonatology. $/ \mathrm{N}$. N. Volodin / / Moscow. - 2004. - 620 p.

9. Vorobyova, O. V. Modern aspects of the pathogenesis of necrotizing enterocolitis. / O. V. Vorobyova / / Neonatology. - 2008. - Vol. 4, № 13. - P. 110-117

10. Vorobyova, V. A. Novopoltseva, E. G., OvsYANNIKOVA, O. B. Enterocolitis in premature infants with intrauterine infection: features of the course and new approaches to therapy./V. A. Vorobyova, E. G. Novopoltseva, O. B. Ovsyannikova / / Questions of gynecology, obstetrics and Perinatology: Scientific and practical journal of the Russian Association of perinatal medicine specialists. - 2008. - Vol. 7, № 6. - P. 37-40

11. Gassan, T. A., Isakov, Yu. F., Krasovskaya, T. V. Surgical treatment of complications of ulcerative necrotizing enterocolitis in newborns./ T. A. Gassan, Yu. F. Isakov / / Problems of modern Pediatrics. 2005. - Vol. 4, № 4. - Pp. 25-27.

12. Golovko, O. K., LeVitskaya, E. M., LyNCheVsKy, G. L. Fatures of management of neonates with necrotizing enterocolitis. /O. K. Golovko, E. M. Levitskaya, G. L. Lynch// Archive for clinical and experimental medicine. - Vol. 11, № 2. - 2002. - P. 241-244.

13. Dolgikh, T. I., Voitovich, M. A., Galileyskaya, S. B., LAzAREVA, L. I. Features of diagnosis of intestinal infection caused by Escherichiacoli O157, complicated by hemolytic-uremic syndrome in young children in the Omsk region./T. I. Dolgikh, M. A. Voitovich, S. B. Galileyskaya, L. I. Lazareva//Herald of Ural medical academic science. - 2009. - № 4 (27). - P. 119-120.

14. Ivanova,O. G., Jonushene,S. V., Ochirov,V. E. The effect of hemodynamically significant arterial duct on the development of necrotizing enterocolitis in preterm neonates with extremely low body mass at birth. /O. G. Ivanova, S. V. Jonushene, V. E. Osherov// Siberian medical journal. - 2011. - Vol. 105, № 6. - P. 262-264.

15. Karavaeva,A. S. Surgical treatment of necrotizing enterocolitis /S. A. Karavaeva// Abstract of dissertation on competition of a scientific degree of candidate of medical Sciences //SPb.-2002. - $42 \mathrm{c}$.

16. Karavaeva, S. A. Diagnosis and clinical features of necrotizing enterocolitis in children. / S. A. Karavaeva / / Bulletin of surgery. I. I. Grekova-2008. - Vol. 161, № 4. - P. 41-44.

17. Karpova, I. Yu., Parshikov, V. V., Batanov, G. B. Experience of surgical treatment of newborns with necrotizing enterocolitis./ I. Yu. Karpova, V. V. Parshikov, G. B. Batanov / / Herald of surgery. I. I. Grekova. - 2012.- № 2.- P. 58-60.

18. Muratov, I. D., Kostenko, V. N., Makhotin, A. A. Surgical aspects of treatment of necrotizing enterocolitis in newborns./I. D. Muratov, V. N. Kostenko, A. A. Makhotin// Surgery. - 1993. No. 8.-Pp. 83-86.
19. Muratov, I. D. Ulcerative-necrotizing enterocolitis of newborns. /I. D. Muratov / / Health Care Of The Far East. - 2004. - № 3.- P. 52-56.

20. Podkamenev,A. V. Pathogenesis and treatment of ulcerative necrotizing enterocolitis and perforations of the gastrointestinal tract in neonates / A. V. Podkamenev// Abstract of dissertation on competition of a scientific degree of candidate of medical Sciences. - Irkutsk 2008. - $42 \mathrm{p}$.

21. Protopopova, N. V., Podkamenev, V. V., PodKAMENEV, A.V. Risk factors for ulcerative necrotizing enterocolitis in newborns./N. V. Protopopov, V. V. Podkamenev, A. V. Podkamenev// Diagnostic issues in pediatrics. - 2010.- № 1.- P. 43-48.

22. Siтko, L. A. Criteria of severity and prognosis of necrotizing enterocolitis in newborns. / L. A. Sitko / / Pediatric surgery. - 2003. - № 6. - P. 46-48.

23. Torlopova,V. A. Prenatal diagnosis and modern aspects of surgical care to infants with malformations of the digestive tract /V. A. Torlopov// Abstract of dissertation on competition of a scientific degree of candidate of medical Sciences. - Moscow 2006. - 24 p.

24. Chernyshev, A. K., Sitko,L. A. Mandrik,T. M., ToropCHENKo,V. N. Criteria of severity and prognosis of necrotizing enterocolitis in newborns. $/ \mathrm{K}$. A. Chernyshev, L. A. Sitko, T. M., Mandrik.V.N. Toropchenko// Pediatric surgery. - 2003.- № 6.- P. 46-48.

25. Chubarova, A. I. Necrotizing enterocolitis in newborns: new aspects of pathogenesis/A. I. Chubarova / / Questions of gynecology, obstetrics and perinatology. - 2003. - Vol. 2, № 1. - P. 62-70.

26. Shabalov, N. P. Neonatology. /N. P. Shabalov// Tutorial: in 2 vols, vol.1, $3^{\text {rd }}$ ed. M.: Medpress-inform. -2004. p. 341-350.

27. Scherbinin, R. L.,Vecherkin,V. A., Rezvan,S. G., KRYUKOV,Y. V. Results of complex treatment of necrotizing enterocolitis in newborns. /R. L. Shcherbinin, V. A. Vecherkin, S. G. Rezvan, Yu. V. Kryukov/ / Pediatric surgery. - 2012.- № 1.- P. 12-15

28. Boston, V. E. Necrotisingenterocolitis and localised intestinal perforation: different diseases or ends of a spectrum of pathology / V. E. Boston // Pediatr. Surg. Int. 2006. - Voi. 22, N 6. - P. 477-484

29. Claud, E., Walker, W. A. Hypothesis: inappropriate colonization of the premature intestine can cause neonatal necrotizing enterocolitis. // FASEB J. - 2001. - Vol.15, №8. - P. 398-403

30. Epelman, M., Daneman, A., Navarro, O.M., MorAG, I. Necrotizingenterocolitis: review of stateof-the-art imaging findings with pathologic correlation. // Radiographics. - 2007.- Vol.27, №2. - P. 285-305.

31. ForD, H. R. Mechanism of nitric oxide-mediated intestinal barrier failure: insight into the pathogenesis of necrotizing enterocolitis / H. R. Ford // J. Pediatr. Surg. 2006. - Vol. 41, N 2. - P. 294-299

32. Linfert, D., Chowdhry, T., RabB, H. Lymphocytes and ischemia-reperfusion injury.//Transplant. Rev. (Orlando). - 2009. - Vol. 23, №1- P.1-10

33. Ng, P.C., Chan, K.Y., Poon, T.C. Biomarkers for prediction and diagnosis of necrotizing enterocolitis. Clin. Perinatol. 2013; 40 (1): 149-159 DOI: 10.1016/j.clp.2012.12.005 